\title{
Intrinsic Point-Defect Balance in Self-Ion-Implanted ZnO
}

\author{
Pekka T. Neuvonen, ${ }^{1,2, *}$ Lasse Vines, ${ }^{1}$ Bengt G. Svensson, ${ }^{1}$ and Andrej Yu. Kuznetsov ${ }^{1}$ \\ ${ }^{1}$ Department of Physics, Centre for Material Science and Nanotechnology, University of Oslo, \\ P.O. Box 1048 Blindern, N-0316 Oslo, Norway \\ ${ }^{2}$ Department of Physics and Astronomy, University of Aarhus, Ny Munkegade 120, 8000 Aarhus C, Denmark
} (Received 16 July 2012; published 3 January 2013)

\begin{abstract}
The role of excess intrinsic atoms for residual point defect balance has been discriminated by implanting $\mathrm{Zn}$ or $\mathrm{O}$ ions into $\mathrm{Li}$-containing $\mathrm{ZnO}$ and monitoring Li redistribution and electrical resistivity after postimplant anneals. Strongly Li-depleted regions were detected in the Zn-implanted samples at depths beyond the projected range $\left(R_{p}\right)$ upon annealing $\geq 600^{\circ} \mathrm{C}$, correlating with a resistivity decrease. In contrast, similar anneals of the O-implanted samples resulted in $\mathrm{Li}$ accumulation at $R_{p}$ and an increased resistivity. Control samples implanted with $\mathrm{Ar}$ or $\mathrm{Ne}$ ions, yielding similar defect production as for the $\mathrm{Zn}$ or $\mathrm{O}$ implants but with no surplus of intrinsic atoms, revealed no Li depletion. Thus, the depletion of $\mathrm{Li}$ shows evidence of excess $\mathrm{Zn}$ interstitials $\left(\mathrm{Zn}_{I}\right)$ being released during annealing of the $\mathrm{Zn}$-implanted samples. These $\mathrm{Zn}_{I}$ 's convert substitutional $\mathrm{Li}$ atoms $\left(\mathrm{Li}_{\mathrm{Zn}}\right)$ into highly mobile interstitial ones leading to the strongly Li-depleted regions. In the O-implanted samples, the high resistivity provides evidence of stable $\mathrm{O}_{I}$-related acceptors.
\end{abstract}

DOI: 10.1103/PhysRevLett.110.015501

PACS numbers: 81.05.Dz, 72.80.Ey, 66.30.Lw, 71.55.Gs

Zinc oxide $(\mathrm{ZnO})$ is a promising material for optoelectronic and sensor applications. Indeed, it has a wide and direct band gap $\left(E_{g} \simeq 3.4 \mathrm{eV}\right)$, suitable for UV or white light sensors or sources, as well as a high exciton binding energy $(\sim 60 \mathrm{meV})$ [1], enabling, for instance, efficient lasing at room temperature (RT). Selective area doping by ion implantation is an important technology for a successful implementation of such devices, but it may also be used as a tool to understand intrinsic point defects when monitoring the evolution of the radiation damage. Previous ion-implantation or -irradiation studies of $\mathrm{ZnO}$ have shown that a significant fraction of the induced disorder disappears already at $\mathrm{RT}$, making $\mathrm{ZnO}$ a remarkably radiation hard material [2-5]. Specifically, $\mathrm{Zn}$ interstitials $\left(\mathrm{Zn}_{I}\right)$ were suggested to be mobile even at temperatures below RT, so that the recombination with $\mathrm{Zn}$ vacancies $\left(V_{\mathrm{Zn}}\right)$ is prominent during bombardment [4]. However, in spite of the high dynamic annealing rates, residual disorder remains in the $\mathrm{Zn}$ sublattice as well as in the oxygen sublattice (oxygen vacancies, $V_{\mathrm{O}}$, and interstitials, $\mathrm{O}_{I}$ ) and, in principle, also antisite defects may form. Notably, it is challenging to discriminate between individual contributions of these intrinsic and fundamental point defects and a common interpretation is often made in terms of an overall implantation induced disorder [5], usually measured by Rutherford backscattering spectrometry. In its turn, chemical profiling, which is highly suitable to study impurities and diffusion, has a limited applicability because intrinsic defects are obviously indistinguishable from substitutional matrix atoms.

Among the growth techniques used for $\mathrm{ZnO}$, the hydrothermal (HT) method is appreciated for its potential scalability to produce good quality, single crystalline wafers [6]. However, a high Li content in $\mathrm{HT} \mathrm{ZnO}$ is an issue of concern and postgrowth treatment is required for its reduction [7,8]; especially, Li exhibits a so-called amphoteric behavior resulting in highly compensated material $[9,10]$. In as-grown $\mathrm{HT} \mathrm{ZnO}, \mathrm{Li}$ resides predominantly on $\mathrm{Zn}$ site [9], forming $\mathrm{Li}_{\mathrm{Zn}}$ acceptors, but can be potentially kicked out to an interstitial donor position $\left(\mathrm{Li}_{I}\right)$ during, for instance, postimplantation anneals [11]. Accordingly, HT $\mathrm{ZnO}$, naturally containing $\sim 2 \times$ $10^{17} \mathrm{Li} / \mathrm{cm}^{3}$, is a suitable model system to identify dominating residual point defects involved in the $\mathrm{Li}_{\mathrm{Zn}}$ kick-out mechanism. Indeed, intriguing Li redistribution in the form of "depletion" or "pile-up" after postimplant annealing have been reported previously in the literature [12] but with a limited understanding.

In order to discriminate between the roles of different kinds of intrinsic defects in $\mathrm{ZnO}$, we have performed selfion implants and, exploiting the high dynamic annealing rate, an excess of the corresponding interstitial defects is anticipated during postimplant heat treatment with the ultimate limit equal to the ion dose. Combining $\mathrm{Li}$ chemical profiling with resistivity measurements, we find convincing evidence for Li depletion caused by excess of $\mathrm{Zn}_{I}$, readily kicking out $\mathrm{Li}_{\mathrm{Zn}}$, while a surplus of $\mathrm{O}_{I}$ causes electrical compensation and no Li-depletion.

$10 \times 10 \mathrm{~mm}^{2} \mathrm{HT} \mathrm{ZnO}$ wafers [c-axis oriented, $\left.(000 \overline{1})\right]$ having an initial resistivity $(\rho)$ and Li concentration in the range of $0.1-0.5 \mathrm{k} \Omega \mathrm{cm}$ and $2-4 \times 10^{17} \mathrm{~cm}^{-3}$, respectively, were used. Excess intrinsic atoms (presumably residing as surplus interstitials) were introduced either by $\mathrm{O}$ or $\mathrm{Zn}$ ion implants. In order to discriminate between these surplus interstitials and those generated in the course of elastic energy deposition (damage formation), $\mathrm{Ne}$ or $\mathrm{Ar}$ 
ion implants were performed with energy and fluence parameters yielding similar disorder profiles as for the $\mathrm{O}$ or $\mathrm{Zn}$ ions, respectively, according to Monte Carlo simulations [13-15]. These control experiments were performed with a so-called "high" fluence $\left(\sim 10^{16}\right.$ ions $\left./ \mathrm{cm}^{2}\right)$ and the corresponding samples were labeled as H_Zn, H_Ar, H_Ox, and H_Ne. In addition, 2 orders of magnitude lower fluence (a so-called "low" fluence and samples labeled as L_Zn and L_Ox) was also used to investigate possible concentration effects for the surplus of selfinterstitials. All the implants were performed at RT with fluxes of $\sim 10^{12} \mathrm{~cm}^{-2} \mathrm{~s}^{-1}$. Further, the wafers were cut into pieces with a typical size of $5 \times 5 \mathrm{~mm}^{2}$, which were subjected to anneals at 600,800 , or $1000^{\circ} \mathrm{C}$ for $1 \mathrm{~h}$ in air using a conventional tube furnace. One piece of the $\mathrm{H} \_\mathrm{Zn}$ wafer was isochronally $(30 \mathrm{~min})$ annealed from 550 to $850{ }^{\circ} \mathrm{C}$ (steps of $25-50{ }^{\circ} \mathrm{C}$ ) in air while another piece was isothermally annealed at $800{ }^{\circ} \mathrm{C}$ in air for durations of 1-318 s using a rapid thermal processing furnace $\left(50{ }^{\circ} \mathrm{C} / \mathrm{s}\right.$ heating ramp and $\sim 100{ }^{\circ} \mathrm{C} / \mathrm{s}$ cooling ramp).

$\mathrm{Li}$ concentration versus depth profiles were measured by secondary ion mass spectrometry (SIMS) employing a Cameca IMS7f microanalyzer. A beam of $10 \mathrm{keV} \mathrm{O}_{2}^{+}$ ions was rastered over a surface area of $125 \times 125 \mu \mathrm{m}^{2}$ and secondary ions were collected from the central part of the sputtered crater. Crater depths were measured with a Dektak 8 stylus profilometer, and a constant erosion rate was assumed when converting sputtering time to sample depth. Calibration of the Li signal was performed using an implanted reference sample and the detection limit was in the low $10^{14} \mathrm{~cm}^{-3}$ range.

After the SIMS measurements, the samples were cleaved with cross sections (edges) such that electrical resistance profiles could be determined employing a VEECO D3100 atomic force microscope operated in scanning spreading resistance mode (SSRM). A conductive Ti-Pt covered silicon tip was used in contact mode and a DC bias voltage was applied between the sample and the tip. The back side contact was obtained by wrapping the samples in a conductive $\mathrm{Cu}$ tape with a droplet of eutectic indium-gallium in between. Generally, SSRM data are of limited quantitative validity but sufficiently accurate for qualitative conclusions. The as-grown samples revealed typically flat SSRM signals in the range of $10^{8} \Omega$ while the as-implanted samples were highly resistive and out of range.

Figures 1(a) and 1(b) show Li concentration and SSRM signal versus depth profiles for the L_Zn, H_Zn, and H_Ar samples. In the L_Zn sample, the $600^{\circ} \mathrm{C}$ annealing does not affect the Li distribution dramatically while $800{ }^{\circ} \mathrm{C}$ results in a decreasing concentration at depths up to $\sim 1 \mu \mathrm{m}$ beyond $R_{p}\left(R_{p} \approx 180 \mathrm{~nm}\right)$. In contrast, for the H_Zn sample a substantial Li depletion occurs already after the $600^{\circ} \mathrm{C}$ anneal. Spectacularly, $800^{\circ} \mathrm{C}$ gives a rise to a depleted region of at least $5.5 \mu \mathrm{m}$ beyond $R_{p}$,
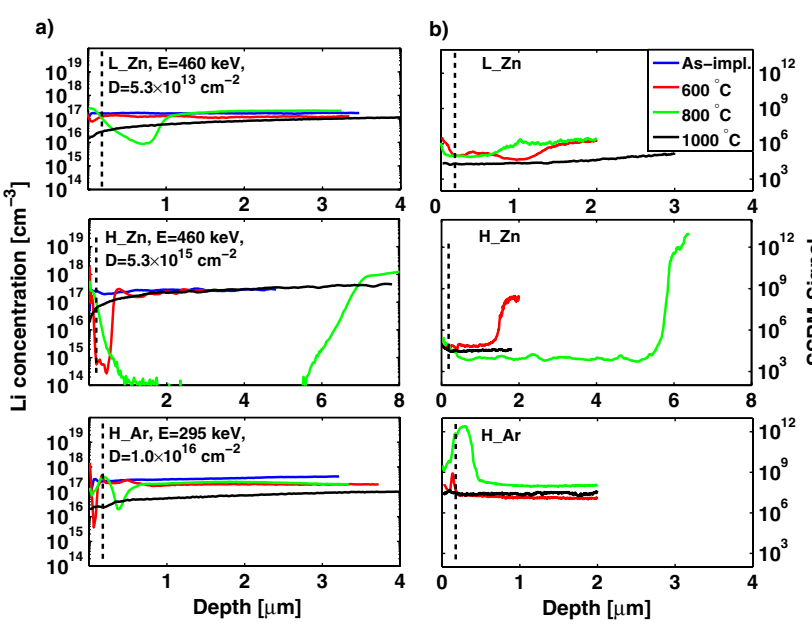

FIG. 1 (color online). (a) Li concentration versus depth profiles measured by SIMS and (b) corresponding SSRM signals for $\mathrm{Zn}$ - and Ar-ion-implanted samples. The annealing time was $1 \mathrm{~h}$ for all the temperatures. The dashed lines indicate $R_{p}$ of the implanted ions $(\sim 180 \mathrm{~nm})$. Notice the difference in depth scale for sample H_Zn due to the deep Li redistribution.

and the residual Li concentration is below the detection limit. These results alone suggest that $\mathrm{Li}$ redistribution is promoted by intrinsic defects because of the pronounced fluence dependence. However, the question on the origin of defects mediating Li redistribution remains, and corresponding Ar implants were undertaken. As illustrated in the lower panel of Fig. 1(a), no broad Li-depleted region appears in the H_Ar samples after 600 and $800^{\circ} \mathrm{C}$, but, instead, some accumulation occurs around $R_{p}$ (surrounded by two narrow Li-lean regions). In general, the overall magnitude of Li redistribution at 600 and $800{ }^{\circ} \mathrm{C}$ is minor in the H_Ar samples compared to that in the H_Zn samples. After $1000^{\circ} \mathrm{C}$, all samples in Fig. 1(a) exhibit rather similar profiles suggesting a substantial removal of the implantation induced defects and minor effect on the Li outdiffusion.

Figure 1(b) reveals a clear resemblance of the SSRM profiles with the SIMS profiles in Fig. 1(a). This is most pronounced for the H_Zn samples annealed at $800{ }^{\circ} \mathrm{C}$, where the Li-depleted region exhibits a low resistivity as unveiled by the abrupt and large step in the SSRM signal. Upon $600^{\circ} \mathrm{C}$ annealing, H_Zn reveals a low resistive region extending slightly deeper than the Li-depleted one, and a close examination of the Li profile shows a buildup beyond the depleted layer. This may indicate that a fraction of the redistributed $\mathrm{Li}$ atoms reside as donors $\left(\mathrm{Li}_{I}\right)$ in this region. Consistent with the minor Li redistribution in the L_Zn samples, the SSRM signal also displays only small variations, with a weak indication of a plateau having an extension close to that of the Li-depleted region after $800^{\circ} \mathrm{C}$. In the H_Ar samples, the SSRM signals are in direct contrast to those in the $\mathrm{H} \_\mathrm{Zn}$ samples with a strong increase around $R_{p}$ and no existence of a low-resistivity 
region. Accordingly, combining the SIMS and SSRM results in Fig. 1, we may conclude that the presence of $\mathrm{Zn}_{I}$ 's plays a decisive role; a surplus of $\mathrm{Zn}_{I}$ 's converts less mobile $\mathrm{Li}_{\mathrm{Zn}}$ acceptors to highly mobile $\mathrm{Li}_{I}$ donors resulting in Li-depleted $n$-type regions with a low resistivity [16].

Figures 2(a) and 2(b) show the Li concentration and SSRM signal versus depth for the L_Ox, H_Ox, and $\mathrm{H} \_\mathrm{Ne}$ samples. Comparing the Li redistribution in the L_Ox and H_Ox samples, a distinct fluence dependence of the amount of Li accumulated around $R_{p}$ upon annealing at 600 and $800{ }^{\circ} \mathrm{C}$ is observed. Further, in direct contrast to the $\mathrm{Zn}$-implanted samples, no depletion of $\mathrm{Li}$ occurs beyond $R_{p}$. The results for the control H_Ne sample confirm that it is not the displacement of matrix atoms but again the surplus of implanted self-ions (oxygen) that governs the $\mathrm{Li}$ redistribution. Note upon the 600 and $800^{\circ} \mathrm{C}$ anneals, the $\mathrm{H} \_\mathrm{Ne}$ and $\mathrm{H} \_$Ar samples display rather similar Li profiles but with some difference in absolute magnitude, presumably caused by the difference in defect production rates between the two ions [17]. In accordance with the data in Fig. 1(a), all samples in Fig. 2(a) annealed at $1000^{\circ} \mathrm{C}$ also show $\mathrm{Li}$ profiles having characteristic "outdiffusion" tails toward the surface.

The resistance evolution in the H_Ne samples after 600 and $800{ }^{\circ} \mathrm{C}$, Fig. 2(b), is almost identical to that in the H_Ar samples, Fig. 1(b), with a peak around $R_{p}$ while deeper regions are more conductive. However, after $1000^{\circ} \mathrm{C}$, the resistance of the H_Ne sample resembles that of the L_Zn and H_Zn samples, while the H_Ar sample exhibits a substantially higher value, as also confirmed by four-point-probe measurements. This may
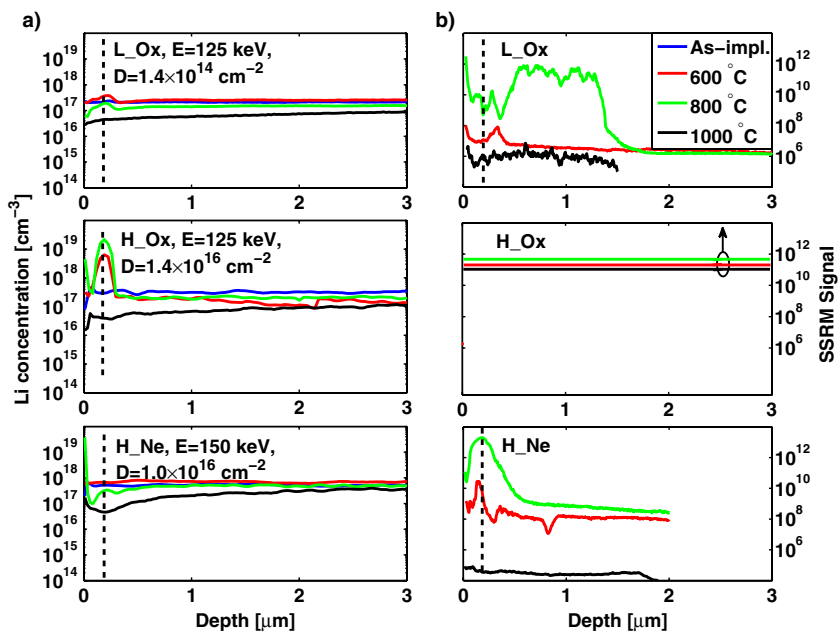

FIG. 2 (color online). (a) Li concentration versus depth profiles as measured by SIMS and (b) corresponding SSRM signals for $\mathrm{O}$ - and Ne-ion-implanted samples. The annealing time was $1 \mathrm{~h}$ for all the temperatures. The dashed lines indicate $R_{p}$ of the implanted ions $(\sim 180 \mathrm{~nm})$. The SSRM data for the H_Ox samples are above the range accessible by our setup. indicate that the higher defect generation per incoming ion during $\mathrm{Ar}$ implants, relative to $\mathrm{Ne}$ implants, gives rise to more stable complexes of intrinsic acceptors, e.g., $\mathrm{O}_{I^{-}}$and/or $V_{\mathrm{Zn}}$-related ones, but further investigations are required to confirm this speculation. For the H_Ox samples, the resistance remained above the maximum range of our setup, irrespective of the annealing temperatures used. This occurs in spite of nominally very similar primary defect production rates for the $\mathrm{Ne}$ and $\mathrm{O}$ ions, again leaving the surplus of implanted self-ions $(\mathrm{O})$ as the most obvious explanation. More insight into the role of surplus $\mathrm{O}$ atoms is obtained by considering the resistance evolution in the L_Ox samples, Fig. 2(b). Between 600 to $800^{\circ} \mathrm{C}$, a region extending $1.4 \mu \mathrm{m}$ beyond $R_{p}$ converts from "low" to "high" resistance, without any significant $\mathrm{Li}$ redistribution. This suggests formation of intrinsic acceptor-like defects activated by the $800^{\circ} \mathrm{C}$ anneal and $\mathrm{O}_{I}$ is a prime candidate. Further work is required for a quantitative determination of the defect reactions involved, but it is obvious that the amount of surplus (implanted) $\mathrm{O}$ ions is a decisive factor (and not the amount of displaced matrix atoms [and corresponding vacancies]).

This striking role of self-ion implantation on the point defect balance in $\mathrm{ZnO}$, as demonstrated in Figs. 1 and 2, shows similarities with the so-called " +1 model" for $\mathrm{Si}$, in which after a certain dose and annealing, the implanted self-ions occur as interstitials agglomorating into large cluster, eventually forming dislocation loops [18]. However, such a strong preferential annealing as observed in the present study is uncommon among most semiconductors; even for those with a high degree of ionicity and also for $\mathrm{GaN}$, which is well-studied and behaves similar to $\mathrm{ZnO}$ with a strong dynamic annealing, such reports are scarce in the literature. On the other hand, one reason may be a lack of efficient means to monitor self-ions in $\mathrm{GaN}$ and metal oxide semiconductors, such as $\mathrm{MgO}, \mathrm{CdO}$, and $\mathrm{CuO}$.

Figure 3 shows Li profiles after (a) isochronal and (b) isothermal annealing of H_Zn samples. The kick-out process starts at $600{ }^{\circ} \mathrm{C}$ and takes place in a relatively narrow region around $R_{p}$, Fig. 3(a), with a pileup after the depleted region (consistent with the data in Fig. 1(a)). The pile-up may be related to the electric field built up at the abrupt $n^{+}-n$-junction formed due to the Li redistribution; the field promotes rapid transport of the $\mathrm{Li}_{I}^{+}$donor from the $n^{+}$-region into the $n$-region where the transport slows down because it is now governed by thermal diffusion only. Hence, at sufficiently low temperatures where the diffusivity is low compared to the electric field effect, a pileup can be expected in the $n$-region. Further annealing gradually advances the depleted region reaching a maximum extension of $\sim 8 \mu \mathrm{m}$ after $750^{\circ} \mathrm{C}$. Then, at $775^{\circ} \mathrm{C}$ a reverse process is initialized and $\mathrm{Li}$ starts to return to the depleted region, as indicated by indiffusion from the surface and an increased average concentration in the depleted region from $<1 \times 10^{14}$ to $8 \times 10^{14} \mathrm{~cm}^{-3}$. This increase 

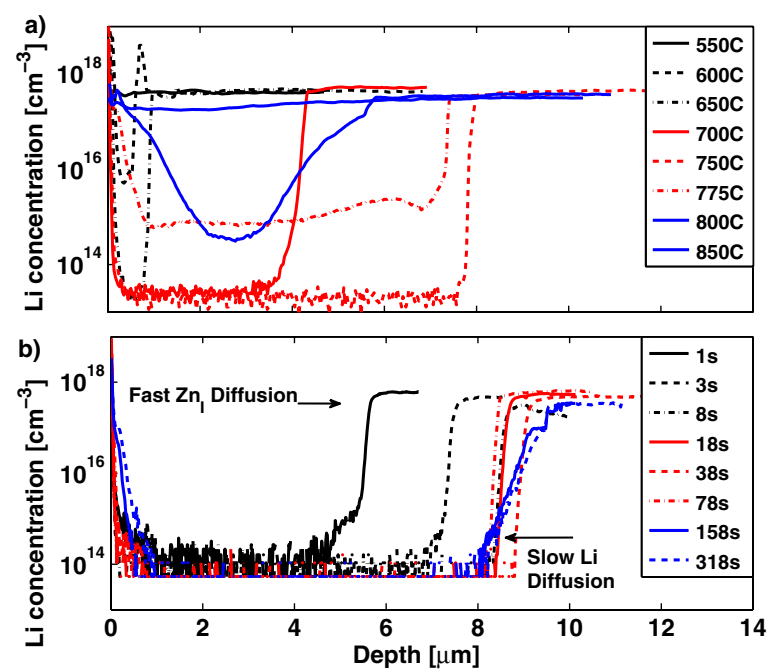

FIG. 3 (color online). Li concentration versus depth profiles as measured for (a) isochronal (30 min) and (b) isothermal $\left(800^{\circ} \mathrm{C}\right)$ anneals of $\mathrm{H} \_\mathrm{Zn}$ samples.

may be associated with a reestablishment of the equilibrium $V_{\mathrm{Zn}}$ concentration, after the source for injection of $\mathrm{Zn}_{I}$ is exhausted. These $V_{\mathrm{Zn}}$ 's are then able to capture $\mathrm{Li}_{I}$ 's, rapidly moving into the depleted layer forming more stable $\mathrm{Li}_{\mathrm{Zn}}$ 's. Annealing at $800^{\circ} \mathrm{C}$ narrows the depleted region by diffusion from both the surface and the bulk. This process is much slower than the one yielding the depletion. Note some $\mathrm{Li}$ atoms always remain in the vicinity of the surface (even after the maximum depletion at $750{ }^{\circ} \mathrm{C}$ ) and can contribute to the "refilling process." The presence of two $\mathrm{Li}$ diffusion mechanisms, as unveiled here, are in accordance with a fast transport of $\mathrm{Li}_{I}$ and a slow, vacancymediated one, of $\mathrm{Li}_{\mathrm{Zn}}$ [16]. Annealing at $850{ }^{\circ} \mathrm{C}$ restores the $\mathrm{Li}$ content to the original bulk level throughout the sample and equilibrium conditions apply.

Figure 3(b) illustrates that the $\mathrm{Zn}_{I}$ 's are released from the implanted region as a burst, and already after $1 \mathrm{~s}$ at $800{ }^{\circ} \mathrm{C}$ (heating rate $50^{\circ} \mathrm{C} / \mathrm{s}$ ) $\mathrm{Li}$ is removed to a depth of $6 \mu \mathrm{m}$. With increasing duration, the depletion region becomes deeper reaching $8 \mu \mathrm{m}$ after $78 \mathrm{~s}$. The source of $\mathrm{Zn}_{I}$ 's is then exhausted and the slow diffusion process controlling the refilling starts to dominate. In fact, this scenario complies with the +1 model for $\mathrm{Si}$ [18], discussed previously, and the associated transient-enhanced diffusion where a burst of self-interstitials promote rapid transport of dopants, like boron, via an interstitial-mediated process [19].

In conclusion, the role of excess intrinsic atoms for the residual point defect balance in $\mathrm{ZnO}$ has been discriminated by implanting $\mathrm{Zn}$ or $\mathrm{O}$ ions into $\mathrm{Li}$-containing samples and monitoring the $\mathrm{Li}$ redistribution as well as the resistivity. Li-depleted regions with an extension of up to $8 \mu \mathrm{m}$ occur beyond $R_{p}$ in the $\mathrm{Zn}$-implanted samples upon anneals at $600-800{ }^{\circ} \mathrm{C}$, correlating with a decrease of the resistivity. In contrast, similar anneals of the
O-implanted samples give rise to $\mathrm{Li}$ accumulation around $R_{p}$ and a strongly increased resistivity. Based on comparison with Ar- and Ne-ion-implanted control samples, it is found that the surplus of implanted intrinsic atoms is decisive for the observed effects. The appearance of the Li-depleted regions is associated with excess of $\mathrm{Zn}_{I}$ 's converting immobile $\mathrm{Li}_{\mathrm{Zn}}$ to highly mobile $\mathrm{Li}_{I}$. Correspondingly, the very high resistivity observed in the O-implanted samples, where no depletion of Li occurs, is associated with $\mathrm{O}_{I}$-related acceptors compensating the native $n$-type doping. The diffusion of $\mathrm{Li}$ exhibits one fast and one slow process, presumably arising from interstitial-mediated $\left(\mathrm{Li}_{I}\right)$ and vacancy-mediated $\left(\mathrm{Li}_{\mathrm{Zn}}\right)$ mechanisms, respectively.

The authors gratefully acknowledge financial support from the Norwegian Research Council through the NANOMAT, FRIENERGI, and FRINAT programs.

*neuvonen@phys.au.dk

[1] D. G. Thomas, J. Phys. Chem. Solids 15, 86 (1960).

[2] D. C. Look, D. C. Reynolds, J. W. Hemsky, R. L. Jones, and J. R. Sizelove, Appl. Phys. Lett. 75, 811 (1999).

[3] S. O. Kucheyev, P. N. K. Deenapanray, C. Jagadish, J. Williams, K. Yano, M. Koike, S. Sasa, M. Inoue, and K. Ogata, Appl. Phys. Lett. 81, 3350 (2002).

[4] L.S. Vlasenko and G.D. Watkins, Phys. Rev. B 72, 035203 (2005).

[5] S. O. Kucheyev, J. S. Williams, C. Jagadish, J. Zou, C. Evans, A. J. Nelson, and A. V. Hamza, Phys. Rev. B 67, 094115 (2003).

[6] K. Maeda, M. Sato, I. Niikura, and T. Fukuda, Semicond. Sci. Technol. 20, S49 (2005).

[7] B. G. Svensson, T. Moe Børseth, K. M. Johansen, T. Masqood, R. Schifano, U. Grossner, J. Christensen, L. Vines, P. Klason, Q. X. Zhao et al., Mater. Res. Soc. Symp. Proc. 1035, L04 (2008).

[8] L. Vines, E. V. Monakhov, R. Schifano, W. Mtangi, F. D. Auret, and B. G. Svensson, J. Appl. Phys. 107, 103707 (2010).

[9] K. M. Johansen, A. Zubiaga, I. Makkonen, F. Tuomisto, P. T. Neuvonen, K. E. Knutsen, E. V. Monakhov, A. Yu. Kuznetsov, and B. G. Svensson, Phys. Rev. B 83, 245208 (2011).

[10] C.H. Park, S. B. Zhang, and S.-H. Wei, Phys. Rev. B 66, 073202 (2002).

[11] P. T. Neuvonen, L. Vines, A. Yu. Kuznetsov, B. G. Svensson, X. L. Du, F. Tuomisto, and A. Hallén, Appl. Phys. Lett. 95, 242111 (2009).

[12] T. Moe Børseth, F. Tuomisto, J.S. Christensen, E. V. Monakhov, B. G. Svensson, and A. Yu. Kuznetsov, Phys. Rev. B 77, 045204 (2008).

[13] Note the initial damage production when implanting selfelements and control elements is not fully identical because of the mass difference and subsequently different density of collision cascades, but it is still similar within a factor of less than two. Further, as shown in the present work, it is the amount of surplus self-interstitials surviving after annealing, 
and not the ballistic generation of initial recoils, that directly matters for the observed redistribution of $\mathrm{Li}$.

[14] J.P. Biersack and L. G. Haggmark, Nucl. Instrum. Methods 174, 257 (1980).

[15] R.E. Williford, R. Devanathan, and W. J. Weber, Nucl. Instrum. Methods Phys. Res., Sect. B 141, 94 (1998).

[16] A. Carvalho, A. Alkauskas, A. Pasquarello, A. K. Tagantsev, and N. Setter, Phys. Rev. B 80, 195205 (2009).

[17] The Li redistribution around $R_{p}$ in the $\mathrm{H} \_\mathrm{Ar}$ and $\mathrm{H} \_\mathrm{Ne}$ samples is similar to that in the L_Zn and H_Zn samples for the $600{ }^{\circ} \mathrm{C}$ anneals. This may indicate that the defects mediating the $\mathrm{Li}$ transport at this temperature originate from matrix recoils surviving recombination, while at $800{ }^{\circ} \mathrm{C}$ the interaction with surplus interstitials dominates.

[18] Y. Zhong, C. Bailat, R. S. Averback, S. K. Ghose, and I. K. Robinson, J. Appl. Phys. 96, 1328 (2004).

[19] P. A. Stolk, H.-J. Gossmann, D. J. Eaglesham, D. C. Jacobson, C. S. Rafferty, G. H. Gilmer, M. Jaraíz, J. M. Poate, H. S. Luftman, and T. E. Haynes, J. Appl. Phys. 81, 6031 (1997). 